\title{
THE EFFECTS OF DIFFERENT ALLOYING ELEMENTS ON THE THERMAL EXPANSION COEFFICIENTS, LATTICE CONSTANTS AND MISFIT OF NICKEL-BASED SUPERALLOYS INVESTIGATED BY X-RAY DIFFRACTION
}

\author{
Florian Pyczak ${ }^{1}$, Bastian Devrient ${ }^{2}$, Hael Mughrabi ${ }^{1}$ \\ ${ }^{1}$ Institut für Werkstoffwissenschaften, Lehrstuhl I, Universität Erlangen-Nürnberg, Martensstrasse 5, D-91058 \\ Erlangen, Germany \\ ${ }^{2}$ now at: Framatome ANP, Freyeslebenstrasse 1, D-91058 Erlangen, Germany
}

Keywords: partitioning behaviour, alloying elements, lattice constants, thermal expansion

\begin{abstract}
The influence of variations of the chemical composition, especially by adding refractory elements, on the lattice parameter and thermal expansion coefficients of nickel-based superalloys was investigated. To analyse these effects in a systematic way, measurements in a series of experimental and commercial alloys with different alloy compositions were performed. The lattice constants of the $\gamma$ and $\gamma^{\prime}$ phases were measured by X-ray diffraction at temperatures between $25^{\circ} \mathrm{C}$ and $1100{ }^{\circ} \mathrm{C}$. The main focus was on the effects of rhenium additions, but alloy compositions containing ruthenium and iridium were also included. It was possible to interpret the changes of the lattice parameters of $\gamma$ and $\gamma^{\prime}$ as effects of certain alloying elements by analysing the local chemical composition of the $\gamma$ and $\gamma^{\prime}$ phases and the partitioning behaviour of the alloying elements between the $\gamma$ and $\gamma^{\prime}$ phases.
\end{abstract}

\section{Introduction}

Solid solution strengtheners like tungsten, molybdenum and rhenium helped to improve the mechanical properties of modern nickel-based superalloys [1]. Especially rhenium additions resulted in remarkably increased mechanical strength [2-4]. To overcome some problems which are associated with the alloying of rhenium, especially with respect to the phase stability of the alloy composition, alternative elements like ruthenium and iridium have also been alloyed in some recently developed nickel-based superalloys with the aim to investigate, whether it is possible to totally or partially substitute rhenium $[5,6]$.

Nevertheless, the most pronounced gains in mechanical strength resulted not from modifications of the alloy composition but from beneficial grain and $\gamma^{\prime}$ precipitate structures [7]. Superalloys which are cast as single crystals with a volume fraction between 60 to $70 \%$ of cuboidal $\gamma^{\prime}$ particles of about $300-500 \mathrm{~nm}$ edge length are the materials of choice for turbine blade applications $[8,9]$. Unfortunately, the initially cuboidal shape of $\gamma^{\prime}$ particles changes during service at elevated temperatures. A directional coarsening or so called "rafting" of the $\gamma^{\prime}$ particles is observed which results in elongated rod- or plate-like shaped $\gamma^{\prime}$ particles [10-17]. The orientation of the $\gamma^{\prime}$ rafts depends on the direction of the external load and the sign of the lattice misfit between the $\gamma^{\prime}$ precipitates and the $\gamma$ matrix phase at the deformation temperature. Unfortunately, in most relevant cases, e.g. in that region of a blade in which the combined action of thermal and mechanical loads is most severe (stress above ca. $150 \mathrm{MPa}$, temperature $\leq 950 \mathrm{C}$, compare [18]), the development of the raft structure leads to a deterioration of the mechanical properties of the alloy $[9,19]$. In this respect, it is interesting to investigate the effects of different alloying elements on the development of the $\gamma / \gamma^{\prime}$ microstructure. As already mentioned above, the driving force for rafting is a combination of external applied stress and the coherency stresses between $\gamma^{\prime}$ and $\gamma$ phase because of the $\gamma / \gamma^{\prime}$ lattice misfit. How a certain alloying element influences the lattice misfit depends on the partitioning behaviour of the element between $\gamma$ and $\gamma^{\prime}$ phase and on how the lattice constant of the phase is influenced by the alloying element. Elements, which increase the lattice constant, but divide evenly between $\gamma$ and $\gamma^{\prime}$, increase the mean lattice parameter of the alloy but will not influence the lattice mismatch, because the lattice constant of both phases will increase.

Nickel-based superalloys are dedicated hightemperature materials. Unfortunately, the lattice misfit and the resulting coherency stresses between the $\gamma$ and $\gamma^{\prime}$ phase change significantly between room temperature and temperatures in the range of the service temperature of nickel-based superalloys between $800{ }^{\circ} \mathrm{C}$ and $1100{ }^{\circ} \mathrm{C}$, due to different thermal expansion coefficients of the two phases $\gamma$ and $\gamma^{\prime}$ [20-24]. By using X-ray diffraction, it is possible to measure the lattice constants of the $\gamma$ and $\gamma^{\prime}$ phase over a wide temperature range and to obtain lattice misfit values from room temperature to temperatures well above $1000{ }^{\circ} \mathrm{C}$.

Due to the small size of the $\gamma^{\prime}$ precipitates and the even smaller width of the $\gamma$ matrix channels a method 
to determine the local chemical composition with high lateral resolution is needed to measure the partitioning behaviour of alloying elements between $\gamma$ and $\gamma^{\prime}$ phase. EDS measurements (energy dispersive spectroscopy) in the transmission electron microscope (TEM) can provide local chemical compositions with the necessary lateral resolution and were applied frequently to nickel-based superalloys to supplement other measurement methods, for example $[3,25,26]$. The present work focuses on the investigation of effects of different alloying elements on the lattice parameters of nickel-based superalloys and the changes of lattice constants and lattice misfit at elevated temperatures. The high-temperature measurements of the lattice misfits were part of the diploma thesis of one of the authors [27].

\section{Experimental}

\section{Specimens}

The investigated alloys are a series of experimental alloys with a directionally solidified grain structure intended as turbine blade materials for industrial gas turbines [28] and additionally the two commercial alloys CMSX-6 and CMSX-4 as examples of materials used to produce airfoil turbine blades. The chemical composition of the series of experimental alloys is based on the alloy composition of the commercial alloy IN792DS. The contents of different alloying elements like rhenium, ruthenium, iridium, aluminium and/or tantalum were varied in the experimental alloys to improve the overall properties. The detailed nominal composition of all investigated alloys is given in table 1 . The nominal chromium level of all experimental alloys was chosen to be $12.5 \mathrm{wt} . \%$, to ensure sufficient corrosion resistance in stationary gas turbine applications, even when an oxidation or corrosion protection coating fails during service. But the alloys ExAl 8 and ExAl 10 have an actual chromium content of only $9.5 \mathrm{wt} . \%$ compared with the nominal content of 12.5 wt.\%. These differences in the chromium content are important for the interpretation of some of the following results. The alloys CMSX-6 and CMSX-4 have a lower chromium content, because hot corrosion is normally not so severe in airfoil applications, due to cleaner fuels and shorter maintenance intervals.

\section{EDS-measurements}

The partitioning behaviour of the different alloying elements was determined by measuring the local chemical composition of the $\gamma$ and $\gamma^{\prime}$ phase in a Philips CM200 TEM using an EDS system. All measurements were performed in scanning mode using an acceleration voltage of $200 \mathrm{kV}$ and a nominal spot size of $5 \mathrm{~nm}$. The orientation of the specimens were chosen to be near [001] by cut- ting a section with the appropriate orientation, which was ground to a thickness of about $70 \mu \mathrm{m}$ and subsequently electrochemically thinned.

In each alloy, measurements in five different $\gamma^{\prime}$ particles and five different positions in the $\gamma$ matrix were done. These results were evaluated in the form of partitioning ratios $k$ which are defined as the concentration of an alloying element in the $\gamma^{\prime}$ phase divided by the concentration of the element in the $\gamma$ matrix:

$$
k_{\gamma^{\prime} / \gamma}=\frac{c_{\gamma^{\prime}}}{c_{\gamma}}
$$

Elements with a tendency to enrich in the $\gamma^{\prime}$ phase have $k$ factors greater than one while elements, which preferently enrich in the $\gamma$ matrix have $k$ factors below one. From the five measurements in each alloy a mean partitioning factor $k$ for each element in this alloy was calculated.

X-ray diffraction

All X-ray diffraction measurements were performed with a double crystal diffraction setup, illuminating the specimens with the copper $K_{\alpha 1}$ line. The geometry is based on a setup proposed by Wilkens and Eckert [29]. The distances between monochromator crystal and specimen and specimen and detector are chosen in such a manner, that instrumental peak broadening is compensated for the diffraction conditions of the (002) diffraction peak of a nickel-based superalloy. The detector is a positionsensitive Braun OED-50 which records an angular spectrum of about $6^{\circ}$ in 2048 channels simultaneously under the applied diffraction conditions.

The specimens with a surface oriented near the [001] direction of the material were mounted on a specimen stage with the possibility to heat up the specimen from room temperature to more than $1100{ }^{\circ} \mathrm{C}$. This specimen stage is inserted in a vacuum chamber to minimise the oxidation of the specimen surfaces, which would decrease the intensity of the X-ray profiles. Measurements were performed every $100{ }^{\circ} \mathrm{C}$ starting from $25{ }^{\circ} \mathrm{C}$ up to $600{ }^{\circ} \mathrm{C}$ and then increasing the temperature further by $50{ }^{\circ} \mathrm{C}$ steps until the maximum temperature of $1100{ }^{\circ} \mathrm{C}$ was reached. By waiting for a holding time of 10 minutes at each temperature, to allow sufficient heat transfer between specimen stage and specimen before recording the X-ray profile, it was made sure that the specimen had attained the intended temperature. All presented data were measured during the heating-up of the different alloys to minimise changes of the lattice constants due to microstructural changes in the specimens during the holding times at elevated temperatures.

The (002) peak of the nickel-based superalloys is measured, which is a combination of the overlapping (002) peak of the $\gamma$ matrix and the corresponding peak of the $\gamma^{\prime}$ phase. Due to the slightly different lattice constants of 
Table 1: Nominal chemical composition of the investigated alloys in wt.\%

\begin{tabular}{c||c|c|c|c|c|c|c|c|c|c|c} 
Alloy & $\mathrm{Ni}$ & $\mathrm{Al}$ & $\mathrm{Cr}$ & $\mathrm{Co}$ & $\mathrm{Mo}$ & $\mathrm{W}$ & $\mathrm{Ta}$ & $\mathrm{Ti}$ & $\mathrm{Re}$ & $\mathrm{Ru}$ & $\mathrm{Ir}$ \\
\hline \hline IN792DS & bal. & 3.4 & 12.5 & 9.0 & 1.9 & 4.0 & 4.0 & 3.9 & - & - & - \\
\hline ExAl 7 & bal. & 3.4 & 12.5 & 9.0 & 1.9 & 4.0 & 4.0 & 3.9 & 3.0 & - & - \\
\hline ExAl 8 & bal. & 3.4 & $12.5^{*}$ & 9.0 & 1.9 & 4.0 & 4.0 & 3.9 & 3.0 & 3.0 & - \\
\hline ExAl 9 & bal. & 3.4 & 12.5 & 9.0 & 1.9 & 4.0 & 4.0 & 3.9 & - & - & 3.0 \\
\hline ExAl 10 & bal. & 3.4 & $12.5^{*}$ & 9.0 & 1.9 & 4.0 & 4.0 & 3.9 & 3.0 & - & 3.0 \\
\hline CMSX-4 & bal. & 5.7 & 6.4 & 9.5 & 0.6 & 6.3 & 6.5 & 1.0 & 2.9 & - & - \\
\hline CMSX-6 & bal. & 4.7 & 10.3 & 5.2 & 3.2 & - & 2.2 & 4.8 & - & - & -
\end{tabular}

*actual chromium content is $9.5 \%$

the $\gamma^{\prime}$ and the $\gamma$ phase in most nickel-based superalloys the shape of the combined $\gamma / \gamma^{\prime}$ peak is asymmetric. By separating the two peaks it is possible to determine the lattice constant of each phase $a_{\gamma^{\prime}}$ and $a_{\gamma}$ and calculate the $\gamma / \gamma^{\prime}$ lattice mismatch $\delta$ :

$$
\delta=\frac{2\left(a_{\gamma^{\prime}}-a_{\gamma}\right)}{a_{\gamma^{\prime}}+a_{\gamma}}
$$

The separation procedure for the peaks is done by mirroring the steeper flank of the peak at a point near the peak maximum producing a symmetric subpeak in this way. This subpeak is subtracted from the overall intensity resulting in an asymmetric subpeak of less intensity. This second subpeak is also mirrored at its maximum, and the resulting symmetric peak is subtracted from the overall intensity resulting in an asymmetric subpeak of higher intensity and a symmetric subpeak of lower intensity. The second mirroring procedure improves the quality of the subpeak with less intensity. The point, where the first peak is mirrored, is chosen in such a way, that in every position the addition of the intensities of the separated subpeaks is lower than the integral intensity and that the ratio of the area fractions of both subpeaks corresponds to the ratio of volume fractions of the $\gamma$ and $\gamma^{\prime}$ phase in the investigated alloy. For the series of experimental alloys the volume fractions have been determined by the so called Blavette method [30]. Because all alloys investigated in this work have $\gamma^{\prime}$ volume fractions between 60 to $75 \%$, the subpeak with the higher area fraction is identified as the subpeak corresponding to the $\gamma^{\prime}$ phase, with the corresponding lattice constant.

\section{Results}

Partitioning behaviour of alloying elements

The averaged $k$-factors of all investigated alloys are plotted in figure 1. The mean quadratic deviation of the $k$ factor of an alloying element in the different alloys compared with the average value is plotted as an error bar in the diagram. It follows from the relatively small error bars that the tendencies of the different alloying elements to enrich either in $\gamma$ or $\gamma^{\prime}$ are nearly independent of the actual chemical compositions of the different alloys. I.e. the $\mathrm{k}$-factor of an alloying element is only slightly influenced by the chemical compositions of the different alloys.

One group of elements, namely rhenium, chromium, ruthenium and, to a smaller extent, cobalt and molybdenum, tend to enrich preferentially in the $\gamma$ matrix phase. In contrast titanium and tantalum and, less pronounced, aluminium are enriched in the $\gamma^{\prime}$ precipitate phase. Tungsten and iridium are nearly equally divided between $\gamma$ and $\gamma^{\prime}$ phase, which is also true for nickel, which has only a slight tendency to enrich in the $\gamma^{\prime}$ precipitates.

\section{Lattice parameters and lattice misfit}

Initial states The average lattice constants, which are defined by the centre of mass of the (002) profile of the alloy, and the $\gamma$ and $\gamma^{\prime}$ lattice constant in the as-received states were measured at $25{ }^{\circ} \mathrm{C}$. All results are given in table 2 . The average lattice constants of the two commercial airfoil alloys CMSX-6 and CMSX-4 are lower with $0.3586 \mathrm{~nm}$ for CMSX-6 or $0.3589 \mathrm{~nm}$ for CMSX-4, respectively, than the

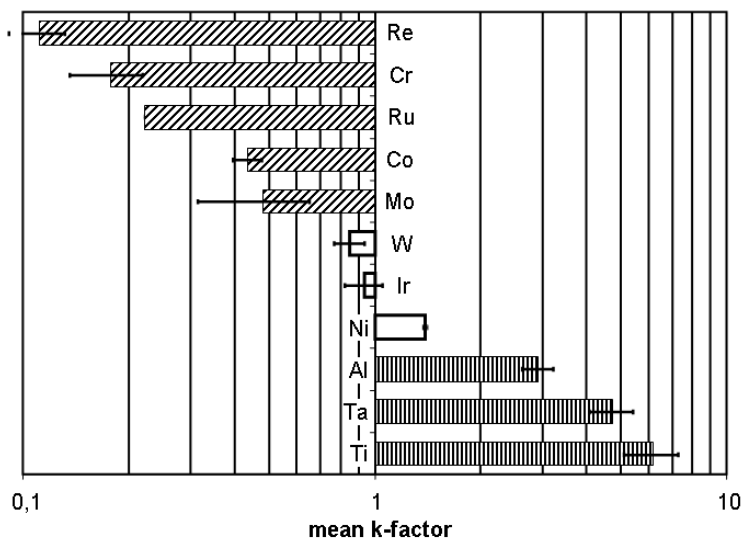

Figure 1: Mean $k$-factor of the different alloying elements in the series of investigated alloys. The error bars mark the mean quadratic deviation of the $k$-factors in the different alloys. 
Table 2: Average $\gamma$ and $\gamma^{\prime}$ lattice constants of the asreceived states at room temperature and lattice misfit $\delta$ at $25^{\circ} \mathrm{C}$ and $1100{ }^{\circ} \mathrm{C}$

\begin{tabular}{c||c|c|c||c|c}
\multirow{2}{*}{\multicolumn{1}{c||}{ Alloy }} & \multicolumn{3}{|c||}{ Lattice constants $\left(25^{\circ} \mathrm{C}\right)$} & \multicolumn{2}{c}{$\delta / 10^{-3}$} \\
\cline { 2 - 6 } & $a_{\text {alloy }}$ & $a_{\gamma}$ & $a_{\gamma^{\prime}}$ & $\delta_{25^{\circ} \mathrm{C}}$ & $\delta_{1100^{\circ} \mathrm{C}}$ \\
\hline \hline IN792DS & 0.3592 & 0.3591 & 0.3593 & +0.4755 & -1.4592 \\
\hline ExAl 7 & 0.3593 & 0.3594 & 0.3592 & -0.4754 & -2.0502 \\
\hline ExAl 8 & 0.3593 & 0.3592 & 0.3592 & +0.1551 & -0.7411 \\
\hline ExAl 9 & 0.3593 & 0.3591 & 0.3594 & +0.7907 & -1.2409 \\
\hline ExAl 10 & 0.3593 & 0.3592 & 0.3593 & +0.4733 & -0.5359 \\
\hline CMSX-4 & 0.3589 & 0.3589 & 0.3587 & -0.6782 & -1.8107 \\
\hline CMSX-6 & 0.3586 & 0.3585 & 0.3586 & +0.3126 & -2.2961
\end{tabular}

lattice constants of the experimental alloys for stationary gas turbine applications, which vary between $0.3592 \mathrm{~nm}$ and $0.3593 \mathrm{~nm}$. CMSX-4 has a higher average lattice parameter than CMSX-6 mainly due to an increased lattice constant of the $\gamma$ matrix in CMSX-4 compared with CMSX-6. The $\gamma^{\prime}$ lattice parameter is in a similar range in both alloys with $0.3587 \mathrm{~nm}$ in CMSX-4 and $0.3586 \mathrm{~nm}$ in CMSX-6.

In the experimental alloys, the lattice parameters of the single phases $\gamma$ and $\gamma^{\prime}$ also vary slightly in the different alloys. Regarding the $\gamma^{\prime}$ lattice constant, IN792DS, ExAl 7 and ExAl 8 have $\gamma^{\prime}$ lattice constants in the range of $0.3592 \mathrm{~nm}$, while the two iridium-containing variants, ExAl 10 and ExAl 9, have a $\gamma^{\prime}$ lattice parameter of $0.3593 \mathrm{~nm}$ and $0.3594 \mathrm{~nm}$, respectively. The $\gamma$ lattice constants in the series of experimental alloys show the lowest values in the alloys IN792DS and ExAl 9 with $0.3591 \mathrm{~nm}$, while the rhenium-containing alloys exhibit increased $\gamma$ lattice constants of $0.3592 \mathrm{~nm}$ in ExAl 8 and ExAl 10 and the highest $\gamma$ lattice parameter of $0.3594 \mathrm{~nm}$ in ExAl 7 . The lattice mismatch results directly from the lattice constants of the $\gamma$ and $\gamma^{\prime}$ phase given above, but it is interesting to list it separately as it provides a value which is normalised with respect to the average lattice constant of the alloys. Thus, the comparison of alloys CMSX-6 and CMSX-4 with the series of experimental alloys is more appropriate by their differences in lattice mismatch. Comparing the lattice mismatches at room temperature, two groups of alloys can be distinguished. The rhenium-free and rhenium- and iridium-containing alloys have positive lattice mismatches between $0.3 \cdot 10^{-3}$ to $0.8 \cdot 10^{-3}$ while the remaining rhenium-containing alloys show negative (ExAl 7 and CMSX-4) or only slightly positive (ExAl 8) lattice mismatches between $0.2 \cdot 10^{-3}$ and $-0.7 \cdot 10^{-3}$.

Temperature dependence The average lattice constants of all alloys increase with increasing temperature, as shown in figure 2. For a clearer display of the relative differences, the changes $\triangle a$ of the average lattice constants, referred to the room temperature values, are plotted versus temperature. The same is done for the plots of the temperature dependence of $\gamma$ and $\gamma^{\prime}$ which are shown in the figures 3 and 4 .

The temperature dependence of the lattice parameters of the alloy and the $a_{\gamma}$ and $a_{\gamma^{\prime}}$ phases can be described with a third order polynominal, which is used to fit the data points measured at different temperatures in the figures 2,3 and 4 .

The temperature dependence of the lattice parameters of the individual phases $\gamma$ and $\gamma^{\prime}$ and the average lattice parameter of the alloys are only similar for lower temperatures. Between $400{ }^{\circ} \mathrm{C}$ and $650{ }^{\circ} \mathrm{C}$ the lattice constant of the $\gamma$ phase starts to increase more rapidly with increasing temperature than the lattice constant of the $\gamma^{\prime}$ phase and the average lattice constant of the alloy. Due to the higher increase of the $\gamma$ lattice constant compared with the $\gamma^{\prime}$ lattice constant, the lattice misfits of all alloys, which are plotted in figure 5 , are negative at temperatures above $800{ }^{\circ} \mathrm{C}$. This is true even for the alloys that have a positive lattice mismatch at room temperature. In the alloys, which have already a negative lattice mismatch at room temperature like ExAl 7 and CMSX-4, the magnitude of the lattice mismatch increases with increasing temperature. In other words, a negative room temperature lattice mismatch becomes even more negative with increasing temperatures in these alloys. The general development of the lattice misfit from positive or slightly negative values at room temperature to negative or more negative values at elevated temperatures is observable in all alloys. But these changes in the lattice misfit versus temperature are much more pronounced in all rheniumfree alloys compared with the rhenium-containing alloys, as is clearly visible in figure 6 , in which all lattice misfits are normalised to $\delta=0$ at room temperature and the range of misfits measured in the rhenium-containing alloys is plotted in comparison to the range of misfits measured in the rhenium-free alloys versus temperature.

Annealed states The lattice mismatch of the series of experimental alloys was measured after an elongated heat treatment at a temperature of $1000{ }^{\circ} \mathrm{C}$ for $500 \mathrm{~h}$. The measurements of the annealed samples were performed at room temperature $\left(\mathrm{T}=25^{\circ} \mathrm{C}\right)$. The alloys IN792DS, ExAl 7, ExAl 8 and ExAl 10 show a pronounced shift of the $\gamma / \gamma^{\prime}$ lattice misfit from positive or slightly negative to negative or more negative values. The effect in ExAl 9 is not so strong, and the lattice mismatch stays positive after the annealing heat treatment, but is also shifted in negative direction like in the other alloys. Two representive profiles for the alloy IN792DS are shown in figure 7 . The profile recorded in the as-received state shows a clear asymmetry, indicating that the $\gamma$ lattice constant is lower than the $\gamma^{\prime}$ lattice constant. So IN792DS has a positive misfit in the as-received state at room temperature 


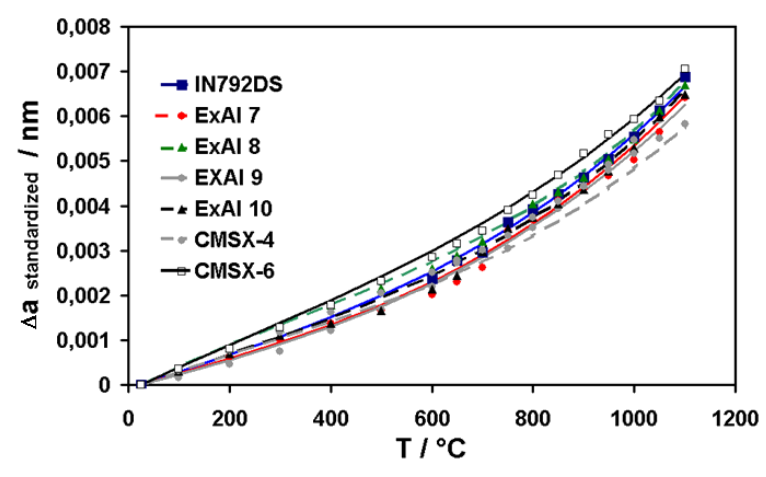

Figure 2: Mean lattice constant (centre of mass of the respective profiles) of the different alloys plotted versus temperature.

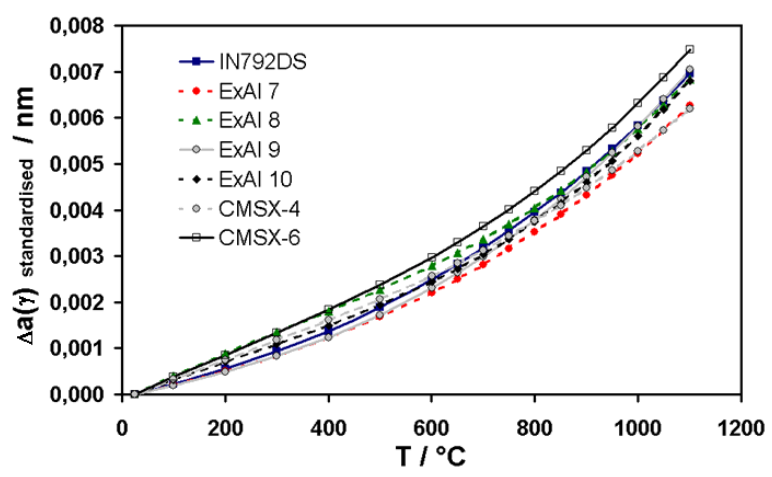

Figure 3: Lattice constant of the $\gamma$ phase of the different alloys plotted versus temperature.

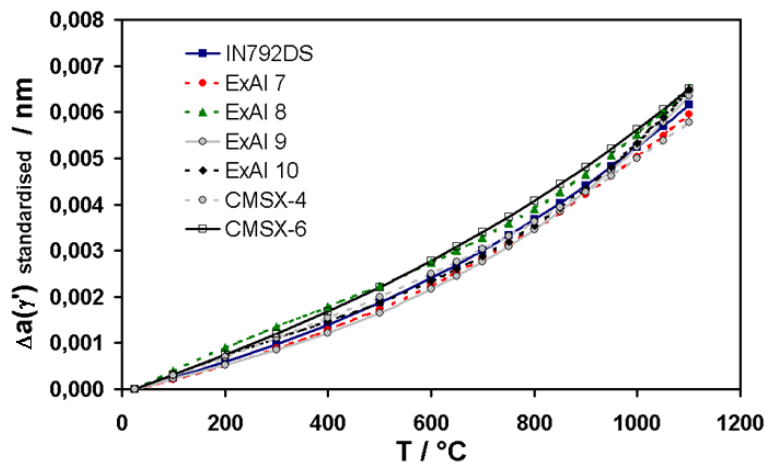

Figure 4: Lattice constant of the $\gamma^{\prime}$ phase of the different alloys plotted versus temperature.

as already mentioned above. After the heat treatment the asymmetry of the profile has been reversed. Now the $\gamma$ lattice constant is larger than the $\gamma^{\prime}$ lattice constant, resulting in a negative lattice misfit after the annealing, compared with the positive lattice misfit of the as-received state.

A similar shift of the lattice misfit as in IN792DS is observed in all other alloys. This behaviour is shown

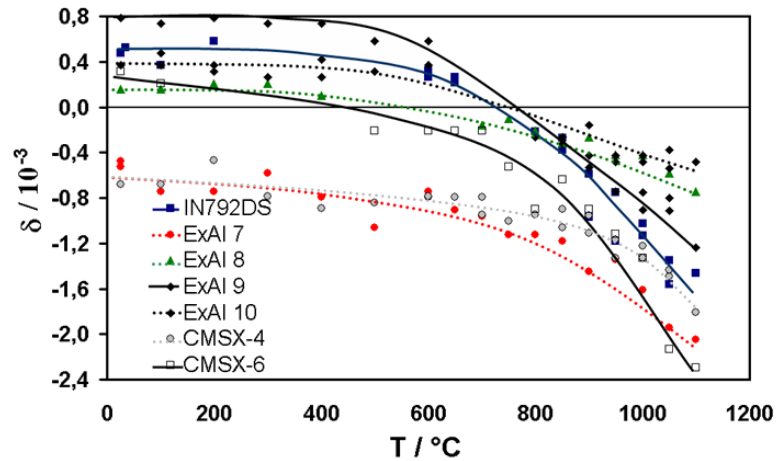

Figure 5: Temperature dependence of the lattice misfit of the different alloys measured between $25{ }^{\circ} \mathrm{C}$ and $1100{ }^{\circ} \mathrm{C}$; the results in the rhenium-containing alloys are plotted as dotted and the results in the rhenium-free alloys as solid lines.

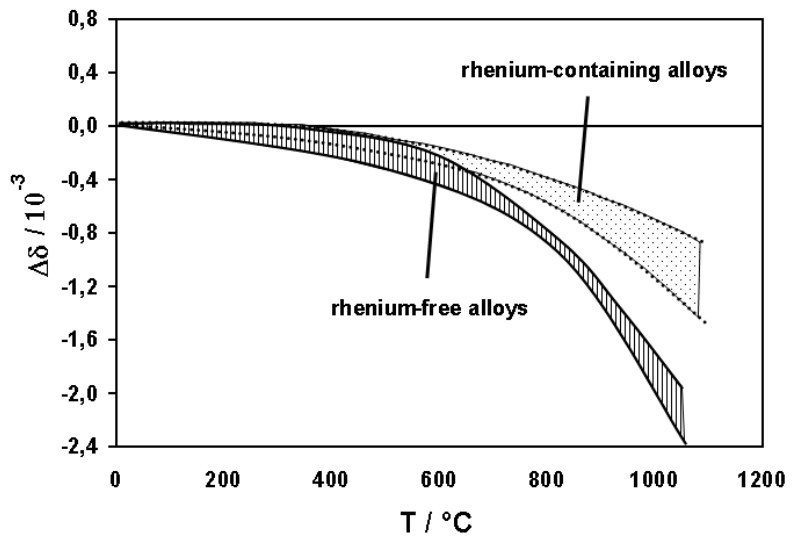

Figure 6: Range of misfits versus temperature measured in the rhenium-containing and rhenium-free alloys. All misfits are normalised to $\delta=0$ at $\mathrm{T}=25^{\circ} \mathrm{C}$.

in figure 8 , where the lattice misfits before and after the heat treatment are plotted for comparison. While these changes in lattice misfit have different magnitudes in the different alloys - most pronounced in ExAl 8 and weakest in ExAl 9 - the tendency to shift the lattice misfit in the negative direction is nevertheless observed in all alloys.

\section{Discussion}

The measured partitioning behaviour of the different elements between $\gamma$ matrix and $\gamma^{\prime}$ phase is in good agreement with results known from literature [31,32]. The partitioning behaviour of the solid solution strengtheners is of special interest. Some are divided equally between $\gamma$ and $\gamma^{\prime}$ like tungsten and iridium, while others like rhenium, ruthenium and molybdenum are enriched in the $\gamma$ matrix. These differences in partitioning behaviour could 


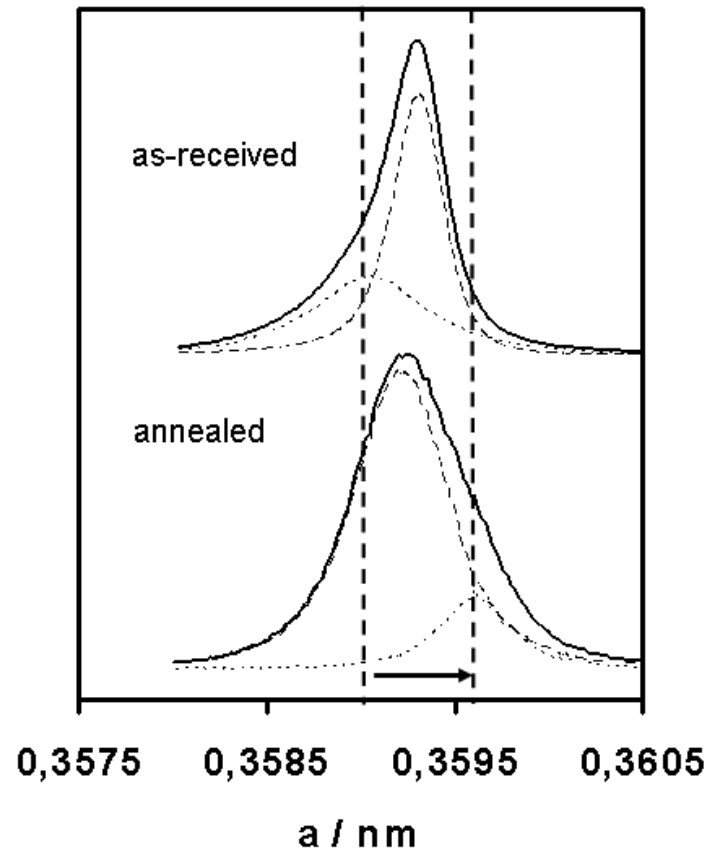

Figure 7: Change of the profile shape before (top) and after (bottom) $500 \mathrm{~h}$ annealing treatment at $1000{ }^{\circ} \mathrm{C}$.

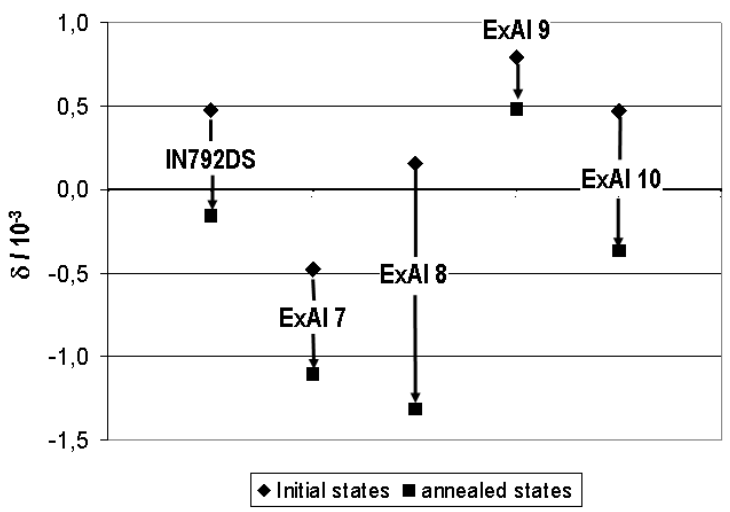

Figure 8: Misfit of the experimental alloys and of IN792DS before and after high temperature heat treatment $(500 \mathrm{~h}$ at $\left.1000{ }^{\circ} \mathrm{C}\right)$

explain why additions of tungsten are not as efficient as a solid-solution strengthener as rhenium additions of the same amount. Alloyed rhenium is nearly fully present in the $\gamma$ matrix, where dislocation movement mainly takes place under normal service conditions, while tungsten also partitions to the $\gamma^{\prime}$ phase. Hence half of the alloyed tungsten does not act as a solid-solution strengthener in the $\gamma$ matrix, where tungsten would most effectively slow down dislocation movement. It is interesting to note in this respect, that the partitioning behaviour of the single el- ements does not change significantly in the different alloys. This is not only true for the series of experimental alloys for stationary gas turbine applications with their chemical composition, which is a variation of the chemical composition of IN792DS, but also for the alloys CMSX-6 and CMSX-4 with a chemical composition, which is quite different from the chemical composition of the series of experimental alloys. It is therefore possible to interpret changes of alloy behaviour in different nickel-based superalloys in dependence of changing contents of single alloying elements, at least qualitatively, without regarding influences of the overall alloy composition on the k-factors of the alloying elements, which are not modified markedly by different alloy compositions.

Most of the changes of the lattice parameters and misfits of the as-received states can be easily explained based on the variations of the chemical composition. In the series of experimental alloys, the lattice constant of the $\gamma$ matrix is increased in all alloys containing rhenium compared with IN792DS. Comparing IN792DS and ExAl 7, it is noted that rhenium additions only influence the $\gamma$ lattice constant, which is increased in ExAl 7, while the $\gamma^{\prime}$ lattice constants of IN792DS and ExAl 7 are nearly the same. Remembering that rhenium strongly enriches in the $\gamma$ phase, it is understandable that rhenium additions solely increase the $\gamma$ lattice constant. An increase of the $\gamma^{\prime}$ lattice constant is measureable compared with IN792DS in the alloys with iridium additions like ExAl 10 and ExAl 9. This finding corresponds with the tendency of iridium to divide equally between $\gamma$ and $\gamma^{\prime}$ phase. So iridium additions should increase the $\gamma^{\prime}$ lattice constant, as it was found in these investigations.

The effects of a combined increase of rhenium and iridium in ExAl 10 or of rhenium and ruthenium in ExAl 8, respectively, are more difficult to interpret. Due to the additionally alloyed rhenium in ExAl 10, compared with ExAl 9, the $\gamma$ lattice constant of ExAl 10 should be further increased. This is only slightly the case. As ruthenium is preferently enriched in the $\gamma$ matrix the lattice constant of the $\gamma$ matrix in ExAl 8 should be larger compared with ExAl 7, where no ruthenium is present in the $\gamma$ phase, which is not the case. This can be understood by the lower chromium content of the alloys ExAl 8 and ExAl 10, compared with the nominal alloy composition, as already mentioned in the experimental section. Chromium is an element, which is also, like rhenium, primarily enriched in the $\gamma$ matrix. Hence, a lower chromium content leads to a lower lattice constant of the $\gamma$ phase, which could partially or fully compensate an increase of the $\gamma$ lattice constant, caused by a higher rhenium, ruthenium or iridium content. The results of the X-ray measurements correspond well with this interpretation of a combined effect of lower chromium and increased ruthenium/iridium content.

The airfoil alloys CMSX-6 and CMSX-4 have both a lower mean lattice constant than the series of experimental 
alloys. This is well explainable with the overall chemical compositions of the alloys. The average content of refractory elements like tungsten, molybdenum or tantalum and also chromium is lower in comparison with the composition of the experimental alloys. Especially CMSX-4 has a low chromium and molybdenum content, only partially compensated by slightly increased tungsten and tantalum contents. The reason is that CMSX-4 has reduced levels of refractory elements to improve the phase stability of the rhenium-containing alloy composition, while the alloy design of CMSX-6 was based on the desire to develop a nickel-based superalloy of low density.

The lattice constant of the $\gamma^{\prime}$ phase is nearly equal in both alloys, while the lattice constant of the $\gamma$ matrix is increased in CMSX-4, which is an effect of the rhenium alloyed to the $\gamma$ phase of CMSX-4.

The lattice misfits at room temperature are most strongly influenced by alloying elements, which preferentially alloy to the $\gamma$ matrix. These elements increase the $\gamma$ lattice parameter and in this way change a positive lattice misfit to lower or even negative values or make a negative lattice misfit more negative. This behaviour is apparent when comparing the alloys IN792DS and ExAl 7, in which a positive lattice misfit is changed to a negative one by rhenium addition or in a similar way, when comparing CMSX-6 and CMSX-4. A less pronounced effect is observed comparing IN792DS and ExAl 8 in which a positive lattice misfit is changed to a lower positive misfit by the elements rhenium and ruthenium. This effect would probably be stronger, if ExAl 8 had the same chromium content as IN792DS. The lower chromium contents could weaken the effects of rhenium and ruthenium, as already mentioned before. The finding that nearly all alloying elements increase the lattice constant of the alloy or the phase to which they primarily partition to is in good agreement with investigations published by Mishima et al. [33] for ternary alloy compositions.

The lattices of both phases, $\gamma$ and $\gamma^{\prime}$, expand with increasing temperature. This results in the increase of the average lattice constant with temperature, which was found for all alloys during these measurements.

A second phenomenom observed in this work is also commonly known from nickel-based superalloys [20, 21]. Above a certain temperature, the thermal expansion coefficient of the $\gamma$ matrix is larger than that of the $\gamma^{\prime}$ phase. This difference in thermal expansion coefficients results in a change of the lattice misfit of the alloy above a certain temperature. A positive lattice mismatch decreases and can even become negative at higher temperatures, while a lattice mismatch already negative at room temperature becomes more negative at elevated temperatures. So even if alloys posses a positive lattice mismatch at room temperature, at which lattice constants and mismatches are most easily measurable, the lattice mismatch at service temperature is in many if not in all cases negative. Hence, every effect or change, especially of the $\gamma^{\prime}$ microstructure, at service temperature is influenced by this negative misfit at elevated temperatures. This development of lattice mismatch versus temperature was already measured by other authors in different nickel-based superalloys [22,34,35].

But it is interesting to note that the temperature dependence of the lattice misfit is noticeably influenced by the presence of the alloying element rhenium in all investigated alloys. In all alloys which contain rhenium, the lattice mismatch does not change so strongly with temperature as in the rhenium-free alloys. This is true for the series of experimental alloys and also for the rheniumcontaining commercial alloy CMSX-4. The variation of the lattice misfit versus temperature, which was measured in CMSX-4 as $\delta_{1100^{\circ} \mathrm{C}}-\delta_{25^{\circ} \mathrm{C}} \approx-10^{-3}$ is in good agreement with results available in the literature for this alloy $[32,34]$. This is especially interesting, because CMSX-4 has a lower average lattice constant than all other alloys investigated in this work except CMSX-6, due to a lower overall content of refractory elements in the alloy composition. Hence, the weaker change of lattice misfit versus temperature of the rhenium-containing alloys, which is also present in CMSX-4, does not seem to be the result of the presence of a higher average amount of refractory elements of any kind in the alloy composition but is due solely to the presence of rhenium. Other alloying elements like iridium do not seem to influence the temperature dependence of the lattice mismatch in this way, which is also visible comparing the alloy IN792DS with the alloy ExAl 9. Both show a similar change of the lattice misfit versus temperature, and the difference of the lattice misfit of the two alloys remains nearly constant in the whole temperature range between $25^{\circ} \mathrm{C}$ and $1100{ }^{\circ} \mathrm{C}$. This is not influenced noticeably by the 3 wt. $\%$ of iridium which are alloyed in ExAl 9 compared with IN792DS. It is not clear at the present state of the investigations, why rhenium delays the change of the lattice misfit versus temperature in the described way. Possible reasons could be the strong tendency of rhenium to enrich in the $\gamma$ matrix, which would explain why rhenium additions mainly decrease the thermal expansion coefficient of this phase, an increase of $\gamma^{\prime}$ solvus due to the presence of rhenium, causing a delayed solving of $\gamma^{\prime}$ builders in the matrix, which would otherwise increase the $\gamma$ lattice parameter or the forming of small clusters by rhenium.

The permanent change of the lattice misfit after extended high-temperature annealing can be explained by plastic deformation, which takes place, due to the coherency stresses between $\gamma$ and $\gamma^{\prime}$ phase at the annealing temperature. This plastic deformation builds dislocation networks at the $\gamma / \gamma^{\prime}$ interfaces, which could also be found in specimens of the annealed alloys, which were investigated in this work. An example of these dislocation networks is shown in figure 9 .

It is known from the X-ray measurements, that the lat- 


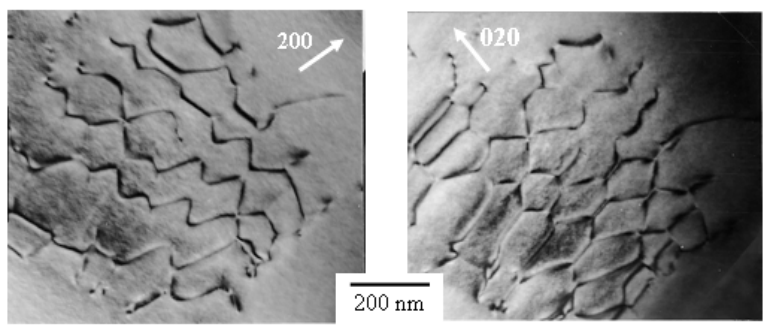

Figure 9: Dislocation network at the $\gamma / \gamma^{\prime}$ interface in an annealed sample of the alloy IN792DS recorded in the transmission electron microscope using two different $\vec{g}$-vectors.

tice misfit at $1000{ }^{\circ} \mathrm{C}$ is negative in all investigated alloys. The $\gamma$ matrix has a larger lattice constant than the $\gamma^{\prime}$ precipitates at the annealing temperature, and the coherency stresses parallel to the $\gamma / \gamma^{\prime}$ interfaces have compressive character in the $\gamma$ matrix and tensile character in the $\gamma^{\prime}$ particles. Dislocation networks, which develop at this temperature to compensate for these coherency stresses, must consist of dislocations with Burgers vectors oriented in such way, that they induce compensating tensile stresses in the $\gamma$ and compressive stresses in the $\gamma^{\prime}$ phase. If the annealing lasts long enough, some kind of equilibrium will be reached at which the internal stresses caused by the dislocations totally compensate the coherency stresses at the high temperature, resulting in a stress-free condition. At this stage, the lattice constants of $\gamma$ and $\gamma^{\prime}$ should be near the so called unconstrained lattice misfit. If the alloy is subsequently cooled down and the lattice constants are measured at room temperature, the $\gamma$ and $\gamma^{\prime}$ lattice constants are influenced by the coherency stresses caused by the room temperature lattice mismatch and the internal stresses stored in the $\gamma / \gamma^{\prime}$ interface dislocation networks. As the dislocation network induces tensile stresses in the $\gamma$ matrix, the $\gamma$ lattice constant will be changed to larger values compared to the situation before the annealing heat treatment. The internal stresses stored in the dislocation network and induced in the $\gamma^{\prime}$ phase have a compressive character and change the $\gamma^{\prime}$ lattice constant to smaller values. Accordingly a negative lattice mismatch in the as-received state becomes even more negative after the heat treatment. If a positive lattice mismatch was present in the as-received state, the magnitude of the lattice mismatch will be decreased or even become zero or negative after the heat treatment. These effects match exactly the changes of the lattice mismatch observed in this work after extended high-temperature annealing in subsequent measurements of the lattice constant at room temperature. It is known from literature, that this effect is not always easily observable by X-ray diffraction. In the case of the alloy SRR99, von Grossmann et al. [36] found no visible shift in the
X-ray profiles after an annealing treatment, because dislocation networks were not fully developed in all matrix channels. But it was shown by convergent beam electron diffraction experiments, that the stress and strain states measured in the present work were present in the $\gamma$ matrix channels containing dislocation networks. A possible reason for the better observability of changes of strain and stress states by X-ray measurements after annealing heat treatments in the present work, may be due to other annealing parameters and different $\gamma^{\prime}$ volume fractions and $\gamma$ channel widths in the alloys investigated in this work compared to the measurements on SRR99.

\section{Conclusion}

The lattice constants and lattice misfits of different nickelbased superalloys were measured by X-ray diffraction at temperatures between $25{ }^{\circ} \mathrm{C}$ and $1100{ }^{\circ} \mathrm{C}$. Additionally, some of the alloys were investigated after an extended annealing at $1000{ }^{\circ} \mathrm{C}$ for $500 \mathrm{~h}$.

It was found that some alloying elements like ruthenium, chromium and especially rhenium partition preferently to the $\gamma$ matrix and increase the lattice constant of that phase, while other elements which partition equally between $\gamma$ and $\gamma^{\prime}$ like iridium increase the lattice constants of both phases nearly equally.

With increasing temperatures, the average lattice constant and the lattice constants of the $\gamma$ and $\gamma^{\prime}$ phases increase. But at higher temperatures the lattice constant of the $\gamma$ matrix increases more rapidly than that of $\gamma^{\prime}$. Hence, the lattice misfits of all alloys are negative at higher temperatures and become more and more negative with increasing temperature.

In all rhenium-containing alloys these changes of the lattice misfit with increasing temperature are less pronounced than in the rhenium-free variants. This effect was found to be independent of the content of other alloying elements.

The lattice mismatch after an extended hightemperature annealing changed from positive or slightly negative values prior to the heat treatment to negative or more negative values. This shift of the lattice mismatch is caused by dislocation networks which develop at the $\gamma / \gamma^{\prime}$ interfaces at the annealing temperature.

\section{Acknowledgement}

A financial grant from the BMBF (German Ministry of Science and Education, Grant No. 03N2011C) is gratefully acknowledged. The investigated alloys were supplied by Doncasters Precision Castings-Bochum GmbH. The authors also want to thank all partners who participated in the development of the ExAl-series of superalloys for the good cooperation. A short but fruitful conver- 
sation with Horst Biermann gave valuable hints for the discussion of the results.

\section{References}

[1] Seth, B.B. "Superalloys — The utility gas turbine perspective". Proc. $9^{\text {th }}$ Int. Symp. on Superalloys, "Superalloys 2000", eds. Pollock, T.M. et al., (Warrendale, PA: The Minerals, Metals and Materials Society, 2000), 3-16.

[2] Anton, D.L. and Lemkey, F.D. "Quinary Alloy Modification of the Eutectic Superalloy $\gamma / \gamma^{\prime}$ plus $\mathrm{Cr}_{3} \mathrm{C}_{2}$ ". Proc. $5^{\text {th }}$ Int. Symp. on Superalloys, "Superalloys 1984", eds. Gell, M. et al., (Warrendale, PA: The Metallurgical Society of AIME, 1984), 603-610.

[3] Giamei, A.F. and Anton, D.L. "Rhenium Addition to a Ni-base Superalloy: Effects on Microstructure", Metall. Trans. A, 16 (1985), 1997-2005.

[4] Blavette, D., Caron, P. and Khan, T. "An Atom Probe Investigation of the Role of Rhenium Additions in Improving Creep Resistance of Ni-base Superalloys", Scripta Metall., 20 (1986), 1395-1400.

[5] Murakami, H., Koizumi, Y. Yokokawa, T., YamabeMitarai, Y., Yamagata, T. and Harada, H. "Atom Probe Microanalysis of Ir-Bearing Ni-based superalloys", Mater. Sci Engg. A, 250 (1998), 109-114.

[6] Caron, P. "High $\gamma^{\prime}$ Solvus New Generation NickelBased Superalloys for Single Crystal Turbine Blade Application". Proc. $9^{\text {th }}$ Int. Symp. on Superalloys, "Superalloys 2000", eds. Pollock, T.M. et al., (Warrendale, PA: The Minerals, Metals and Materials Society, 2000), 737-745.

[7] Ross, E.W. and Sims, C.T. "Nickel-Base Alloys". SUPERALLOYS II, eds. Sims, C.T. et al., (New York: John Wiley \& Sons, 1987), 97-133.

[8] Nathal, M.V., Diaz, J.O. and Miner, R.V. "High Temperature Creep Behaviour of Single Crystal Gamma Prime and Gamma Alloys". Proc. MRS Symp., Vol. 133, eds. Liu, C.T. et al., (Pittsburgh, PA: MRS, 1989), 269-274.

[9] Mughrabi, H. " $\gamma / \gamma^{\prime}$ Rafting and its Effect on the Creep and Fatigue Behaviour of Monocrystalline Superalloys". The Johannes Weertmann Symposium, eds. Arsenault, R.J. et al., (Warrendale, PA: The Minerals, Metals and Materials Society, 1996) 267278.

[10] Nabarro, F.R.N. "Rafting in Superalloys", Metall. Mater. Trans. A, 27 (1996), 513-530.
[11] Feller-Kniepmeier, M. and Link, T. "Formänderung der $\gamma^{\prime}$-Ausscheidungen in einer einkristallinen NiBasislegierung unter dem Einfluss von Temperatur und Zugspannung", Z. Metallkunde, 75 (1985), 283287.

[12] Kraft, S., Altenberger, I. and Mughrabi, H. "Directional $\gamma-\gamma^{\prime}$ Coarsening in a Monocrystalline NickelBased Superalloy during Low-Cycle Thermomechanical Fatigue", Scripta Metall. Mater., 32 (1995), 411416 .

[13] Peng, Z., Glatzel, U. and Feller-Kniepmeier, M. "Change of Phase Morphologies during creep of CMSX-4 at 1253 K", Scripta Mater., 34 (1996), 221226.

[14] Véron, M., Bréchet, Y. and Louchet, F. "Directional Coarsening of Nickel Based Superalloys: Driving Force and Kinetics". Proc. $8^{\text {th }}$ Int. Symp. on Superalloys, "Superalloys 1996", eds. Kissinger, R.D. et al., (Warrendale, PA: The Minerals and Materials Society, 1996), 181-190.

[15] Fährmann, M., Fährmann, E., Paris, O., Fratzl, P. and Pollock, T.M. "An Experimental Study of the Role of Plasticity in the Rafting Kinetics of a Single Crystal Ni-Base Superalloy". Proc. $8^{\text {th }}$ Int. Symp. on Superalloys, "Superalloys 1996", eds. Kissinger, R.D. et al., (Warrendale, PA: The Minerals, Metals and Materials Society, 1996), 191-200.

[16] Kuhn, H.-A., Biermann, H., Ungár, T. and Mughrabi, H. "An X-Ray Study of CreepDeformation Induced Changes of the Lattice Mismatch in the $\gamma^{\prime}$-Hardened Monocrystalline NickelBase Superalloy SRR99", Acta Metall. Mater., 39 (1991), 2783-2794.

[17] Mughrabi, H., Ott, M. and Tetzlaff, U. "New Microstructural Concepts to Optimize the HighTemperature Strength of $\gamma^{\prime}$-Hardened Monocrystalline Nickel-Based Superalloys", Mater. Sci. Engg. A, 234-236 (1997), 434-437.

[18] Draper, S., Hull, D. and Dreshfield, R., "Observations of Directional Gamma Prime Coarsening during Engine Operation", Metall. Trans. A, 20 (1989) 683-688.

[19] Tetzlaff, U. and Mughrabi, H. "Enhancement of the High-Temperature Tensile Creep Strength of Monocrystalline Nickel-Base Superalloy by PreRafting in Compression". Proc. $9^{\text {th }}$ Int. Symp. on Superalloys, "Superalloys 2000", eds. Pollock, T.M. et al., (Warrendale, PA: The Minerals, Metals and Materials Society, 2000), 273-282. 
[20] Nathal, M.V., MacKay, R.A. and Garlick, R.G.: Temperature Dependence of $\gamma-\gamma^{\prime}$ Lattice Mismatch in Nickel-base Superalloys, Mater. Sci. Engg., 75 (1985) 195-205.

[21] Müller, L., Link, T. and Feller-Kniepmeier, M. "Temperature Dependence of the Thermal Lattice Mismatch in a Single Crystal Nickel-Base Superalloy Measured by Neutron Diffraction", Scripta Metall. Mater., 26 (1992), 1297-1302.

[22] Biermann, H., Strehler, M. and Mughrabi, H. "High temperature X-ray study of local lattice parameter changes in deformed and undeformed Samples of the monocrystaline nickel-base superalloy SRR99". Proceedings of EUROMAT 94 TOPICAL, eds. Vorsatz, B. and Szöke, E., (Balatonszéplak, Hungary, 1994), 33-37.

[23] Biermann, H., Strehler, M. and Mughrabi, H. "Hightemperature X-ray measurements of the lattice mismatch of creep-deformed monocrystals of the nickelbase superalloy SRR99". Scripta Metall. Mater., 32 (1995), 1405-1410.

[24] Biermann, H., Strehler, M. and Mughrabi, H. "Hightemperature measurements of lattice parameters and internal stresses of creep-deformed monocrystalline nickel-base superalloy". Metall. Trans. A, 27 (1996), 1003-1014.

[25] Wanderka, N. and Glatzel, U. "Chemical composition measurements of a nickel-base superalloy by atom probe field ion microscopy", Mat. Sci. Engg. A, 203 (1995), 69-74.

[26] Rüsing, J., Wanderka, N., Czubayko, U., Naundorf, V., Mukherji, D. and Rösler, J. "Rhenium distribution in the matrix and near the particle-matrix interface in a model Ni-Al-Ta-Re superalloy", Scripta Mater., 46 (2002), 235-240.

[27] Devrient, B. "Röntgenographische Präzisionsbestimmung der lokalen Gitterkonstante und Gitterfehlpassungen von Nickelbasis-Superlegierungen bei Temperaturen bis zu $1100{ }^{\circ} \mathrm{C} "$, (Diploma thesis, Universität Erlangen-Nürnberg, 2002).

[28] Bürgel, R., Grossmann, J., Lüsebrink, O., Mughrabi, H., Pyczak, F., Singer, R.F. and Volek, A. "Development of a new alloy for directional solidification of large industrial gas turbine blades" (Paper accepted for Proc. of the $10^{\text {th }}$ Int. Symp. on Superalloys, "Superalloys 2004").

[29] Wilkens, M. and Eckert, K. Röntgenographische Untersuchungen über die Versetzungsanordnung in plastisch verformten Kupfereinkristallen" Z. Naturf., 19a (1964), 459-470.
[30] Blavette, D., Caron, P. and Kahn, T. "An atomprobe study of some fine-scale microstructural features in Ni-based single crystal superalloys". Proc. $6^{\text {th }}$ Int. Symp. on Superalloys, "Superalloys 1988", eds. Reichmann, S. et al., (Warrendale, PA: The Metallurgical Society of AIME, 1988), 305-314.

[31] Murakami, H., Honma, T., Koizumi, Y. and Harada, H. "Distribution of Platinum Group Metals in NiBase Single-Crystal Superalloys". Proc. $9^{\text {th }}$ Int. Symp. on Superalloys, "Superalloys 2000", eds. Pollock, T.M. et al., (Warrendale, PA: The Minerals, Metals and Materials Society, 2000), 747-756.

[32] Siebörger, D., Brehm, H., Wunderlich, F., Möller, D., and Glatzel, U. "Temperature dependence of lattice parameter, misfit and thermal expansion coefficent of matrix, $\gamma^{\prime}$ phase and superalloy", Z. Metallkd., 92 (2001), 58 .

[33] Mishima, Y., Ochiai, S., Suzuki, T. "Lattice Parameters of $\mathrm{Ni}(\gamma), \mathrm{Ni}_{3} \mathrm{Al}\left(\gamma^{\prime}\right)$ and $\mathrm{Ni}_{3} \mathrm{Ga}\left(\gamma^{\prime}\right)$ solid solutions with additions of transition and B-subgroup elements", Acta Metall., 33 (1985), 1161-1169.

[34] Yokokawa, T., Ohno, K., Murakami, H., Kobayashi, T., Yamagata, T. and Harada, H. "Accurate Measurement of Lattice Misfit Between $\gamma$ and $\gamma^{\prime}$ Phases in Nickel-Base Superalloys at High Temperature", Adv. X-Ray Analysis 39 (1997), 449-456.

[35] Bruno, G., Schönfeld, B. and Kostorz, G. "Lattice misfit in CMSX-4-like nickel-base superalloys and its temperature dependence", Z. Metallkd., 94 (2003), $12-18$.

[36] von Grossmann, B., Biermann, H., Tetzlaff, U., Pyczak, F. and Mughrabi, H. "Measurement of the Local Elastic Strains in Aged Monocrystalline NickelBase Superalloys by CBED", Scripta Mater. 43 (2000), 859-864. 